\title{
Secondary Stage Students' Possession Degree of Self-Organized Learning Components in the Curriculum of Mathematics
}

\author{
Khaled Abu Loum ${ }^{1} \&$ Adnan A. AL-Omari ${ }^{2}$ \\ ${ }^{1}$ Associate Professor of Mathematics Education, Dep. of Curriculum and Instruction - College of educational \\ sciences, University of Jordan, Jordan \\ ${ }^{2} \mathrm{PhD}$ Candidate, College of educational sciences, University of Jordan, Jordan \\ Correspondence: Adnan A. AL-Omari, College of educational sciences-University of Jordan, Jordan. E-mail: \\ adnanomari2012@yahoo.com
}

Received: February 27, 2018

Accepted: March 6, 2018

Online Published: May 29, 2018

doi:10.5539/mas.v12n6p86

URL: https://doi.org/10.5539/mas.v12n6p86

\begin{abstract}
This study aims at investigating secondary stage students' possession degree of self-organized learning components in the curriculum of mathematics. The sample of the study consisted of first secondary classes in state schools in the Directorate of II Amman whose number reached 925 male and female students randomly selected at the first semester of 2015/2016. To achieve the objectives of the study a questionnaire consisting of 48 items was adopted. Results revealed that the possession degree of these students for the components of self-organized curriculum was medium in all domains and areas. Also, there are no statistically significant differences in the possession degree for first secondary class degree that can be attributed to the variables of social Pattern and the pattern of the study.
\end{abstract}

Keywords: self-organized learning, secondary stage, mathematics curriculum, learning components

\section{Introduction}

The teaching process has developed recently; it has no longer depended on spoon feeding techniques but has depended fully on a set of modern strategies that fit time and its changes. Students have become a centre of these changes as $\mathrm{s} / \mathrm{he}$ is no longer a passive recipient but $\mathrm{s} / \mathrm{he}$ took a great role in planning and organizing the lesson. In this time, the main objective of education is not knowledge any more, but to gain the skills of self-organized learning and to be able to reach the main recourses of data and to employ it in solving their daily problems.

After psychologists had switched their focus on behavioral theoretical principles in explaining the process of learning and teaching, they have become in the seventies fully paying attention to cognitive theoretical approaches (Paris, Lipson and Wixson, 1999) as this theory looks to the learning process as responses that are capable for measuring and are strengthened by practice and enhancement, whereas cognitive theories look at the process as internal mental operations and processes expressed with the learners' capability to envision the data and be aware of them, comprehend them, revise them and use them in similar attitudes (Kazem and Soheil, 2008, p 20).

Cognitive theory focuses on individual's acquisition of knowledge through internal mental constructions in an attempt to achieve cognitive balance, which assumes change in cases of knowledge for learners when interacting with the experiences he faces, where he focuses on analyzing the mental processes. Not only does it focus on interacting with experience and the methods of using them along with organizing and revising them, it also focuses on what learners know and how he develops his expertise and cognitive constructs. It further hypothesizes that the development of learners' experiences are no more than a mental activity that involves the processes of expertise and attitudes and organize them (Qotami 2004, p 10).

Cognitive theory gives more weight to learner's mental processes considering him a lively and active individual, organized and symbolizing knowledge. It therefore stores the cognitive constructs available for him in an attempt to employ them in new attitudes, especially that the process of learning is centered in learning new strategies, organizational and mental ones, in an attempt to make the learner's experience active, understandable and transferable (Ghanem, 2007, p 33).

Cognitive theory, in general, focuses on using feedback related to identifying the results of the learner about his performance and organized procedures which he experiences for the sake of supporting and directing the mental 
connections. It also looks at identifying the previous learner's ability to and readiness through the proper cognitive constructs which provide him with mental readiness to interact with the new experiences aiming at modifying his constructs and enriching them in addition to activating the stored ones and maintaining on continuing in a specific learning attitude and guiding the process of learning (Qotami and Yousef, 2010, p 21).

The roots of cognitive theory are relevant to the social learning theory that appeared in 1941 by Miller and Dollar who published their book about social learning and imitation. Their theory depends on motivation and penalty and copying the patterns. They started paying more attention to cognitive factors included in cognitive and theoretical ones. Human is not only a machine that responds to the patterns and imitates them automatically but individuals possess abilities. Among the most common scholars who had a great influence on the social learning theory is Bandura (1986) who issued a theory about Cognitive social learning in his book Social Foundation of Thought \& Action and social Cognitive Theory in 1986?

Cognitive and social theory is based on a number of assumptions related to active learning, deputy learning and mutual inevitability and learning through observation and finally the minor processes that compose self-organized learning. Below we review these assumptions,

1. Active learning: cognitive social learning is considered a mental activity represented in processing data that are changed from knowledge about the actions and deeds into symbolic representations that work as guides for performance. Learning is normally active through special performance through observing a pattern performance whether it is verbal or dynamic or mental or per formative, a live or electronic (Bandura; 1986, Schunk 2000).

2. Mutual inevitability: Bandura discusses the human behavior in light of the mutual interaction and environmental variables along with the personal ones. Individuals from the perspective of Bandura have no internal motives that motivate their behaviors and their performance therefore can't be automatically controlled through these environmental variables but individuals responses can be explained through a triinteraction where behavior personal factors including knowledge and environmental events among one another, where each factor acts as a determiner for the other factors (Bandura 1986).

3. Learning via observation which means acquiring patterns from behaviors that can never be performed before exposing the individuals to the pattern. Too many behaviors can be learnt through observing others' behaviors then by copying them. It not necessarily that individual should undergo a special experience to directly learn it but as long as he observes others doing the same behavior is enough to learn that behavior. Much of human learning is done through observing others do a particular behavior to let learning take place or by reading about this behavior or seeing images about it (Al-Ghadban, 1996 p. 47).

4. Minor processes for self-organized learning: cognitive social theory views self organized learning as it includes three processes: self observation, self judgment, and self-reaction. Khalifah $(2007,2004)$ emphasizes on the significance of bringing up minds and watching thinking in addition to teaching the trainees on the different life skills such as taking responsibility for everything related to his learning style such as identifying the major purposes of learning, shaping them and guiding them in an attempt to reach its goals, objectives and methods.

Self-organized learning represents a new trend for achievement. Students' achievement investigates its relation with students' ability or quality or domestic environment. However, self-organized theory focuses on how they can activate, modify and motivate themselves with practices that teach them special educational practices. Accordingly, even high achiever students may not achieve well because of their failure in using or controlling the processes of cognitive, emotional and dynamic learning (Zimmerman, 2006)

Al Bana (2013) has pointed out certain features students who are self-organized might enjoy. Among these features is that they take part in their personal learning processes, possess high levels of knowledge about learning strategies, are able to choose lots of these strategies effectively, modify their learning manners, while they don't use modern strategies of learning such as planning, setting up goals and objectives, but they realize the effect of these strategies in the different learning strategies ad know why and when to use these strategies (Zimmerman 1990).

Zimmerman (1990) defines self-organized learning as "students' participation in their learning process with cognitively, motivation-like and behavioral with an active manner in an attempt to achieve their academic objectives that include knowing the general concepts, knowing the way to how deal with difficult missions and knowing when and why to use the different patterns of learning of measurement.

\subsection{Research Problem}

The ministry of education has extensively sought to develop the educational curricula and so they started to develop 
the mathematics curriculum. The modern techniques of teaching methods such as lecturing have become inappropriate with modern methods because students there are considered the main component, but there are a number of students who don't possess the strategies that help them organize their learning despite the many attempts to motivate students' self-organized learning. Still, many students on all levels and in different areas of specializations still lack self-organized learning (Ghanem 2007).

Throughout researchers fieldwork as a teaching staff at the University of Jordan, he noticed that students lack the components of self-learning which motive him, along with the co-author, to identify the degree of students' possession of self-organized learning as the traditional prevailing technique of lecturing is the only one adopted in teaching, and that students role is no more than a recipient.

\subsection{Research Questions}

What is the degree where secondary stage students possess the content of self-organized learning in the mathematics curriculum?

The major question is twofold:

1. What is the degree where secondary stage students possess the content of self-organized learning in the mathematics curriculum?

2. Do subjects' responses in the sample of the study differ in the degree of secondary stage students' possession of the content of self-organized learning in the mathematics curriculum?

\subsection{Significance of the Study}

\subsubsection{Theoretical Significance}

The Theoretical Significance of the study lies in the nature of the subject as it investigates secondary stage students' possession of the content of self-organized learning in the mathematics curriculum with the domains of management, environment, learning of behavior, research and learning data and the non-adaptive organizational behavior.

\subsubsection{Practical Significance}

Here arises the significance of the role played by self-organized learning for students in reinforcing the teaching of mathematics and also its results could be significant for teachers and supervisors as it enlighten them about the systems of learning adopted by students. It further helps students identify, choose and develop strategies of selforganized learning for students according to their preferable methods which has a positive relation with those strategies.

\subsection{Limitations of the Study}

This study is limited to the following issues

1. Place limitations by including areas related to Amman, the capital.

2. Time limitations, being restricted to the first semester of 2015/2016.

3. Human limitations: students of the first secondary class in the directorate of Amman II, vocational and academic streams.

4. Subject-matter limitations where the researchers have adopted a a questionnaire of three domains: management, environment, learning of behavior, research and learning data and the non-adaptive organizational behavior, yet using a descriptive approach for the present study.

\subsection{Definition of Terms}

Possession degree: means what students of secondary stages possess of self-organized learning in mathematics curriculum through the degree they score in the questionnaire.

Self-organized learning: refers to student's ability to learn and conduct environment for learning process management research, and use different sources to get information and to monitor the process of learning and teaching materials. Nofal 0.2011: 106 defines this term as a set of strategies used by the learner to organize job performance or work in order to achieve the objectives of learning. It is also a structural process where active learners develop their learning goals, and then monitor, regulate and control their knowledge and their motives and behavior-oriented manners (Pintrich, 2005: 453). It is also defined as an self-procedurally organized learning as: subjective process based on the activity of learners, through which scientific and literary branch, informatics, industrial students at secondary schools in the capital, Amman, plan learning setting goals and monitor learning, and evaluate the performance and management of different sources in an environment that encourages self- 
regulation in order to improve their skills in Math subject.

\subsection{Literature Review}

The researchers reviewed the research and previous studies that are relevant to the current study, which enables them to access and benefit from them, and note the lack of studies on self-organized and/or self-structured learning in Math, prompting to expand the circle of search and reunion organized self -learning in different materials and to facilitate the presentation of this research the studies, it has been arranged chronologically from oldest to newest, then comments on previous studies in general, as follows,

Khalifa's study (2007) identifies the impact of an educational program in light of some self-organized learning strategies to solve math problems and defend academic achievement among talented students who are low achievers in mathematics, the sample study consisted of 30 pupils, using the diagnosis of gifted students who are low achievers in scale mathematics, and the measure of mathematical problem-solving, and achievement test in algebra and geometry and scale strategies for academic achievement motivation, tutorial in light of some selforganized learning strategies, and the results indicated that psychological intervention through based tutorial on some self-organized learning strategies had a positive impact when the content is consistent with the purpose for which it was designed, which played essential role in improving mathematical problem-solving strategies.

Banna (2013) condcuted another study that aimed to measure the proposed strategy in light of self-organized learning and its role in developing self-regulation skills and achievement in Engineering for the third-graders middle school-. The study adopted a quasi-experimental approach applied on a sample of (82) male and female students. Banna's study adopted a number of tools for the scale of self-regulation skills to learn.

Zankor's study (2013) aimed at investigating the effect of the interaction of a software based on computer simulations of the forms of engineering three-dimensional in the development of visual thinking and learning selforganized skills in second grade average students in Al-Baha region, the study followed the quasi-experimental method, and included tools that represented in interactive software in a simulated three-dimensional geometric shapes and tested the visual thinking in mathematics, to measure the dimensions of self-organized learning skills. The study sample consisted of 80 students, males and females. The results indicated the presence of significant differences between the mean scores of the experimental group students and the control group.

Hashim's study (2014) aimed at identifying the effectiveness of a teaching proposed model based on the strategic learning achievement and skills of self-organization of sports development. The study followed two main approaches: descriptive and quasi-experimental. It was formed achievement test tool and a measure of selfregulation mathematical skills; the study sample consisted of ( 80 students). The results, in general, indicated to the effectiveness of the use of the proposed teaching model in both: the achievement and some self-regulation sports skills development among students in the experimental group.

Castello (2014) conducted a prospective study in order to identify the effective strategies used by (19) doctoral student when regulating operations of writing academic texts and the difficulties they face. The study analyzed students' knowledge about the steps of the written expression as well as the feelings associated with it also analyzed their concepts about academic writing, strategies for revision in drafts that they have written, and the quality of the final review. The results showed a correlation between self-regulation and the quality of the written text and the book's ability to connect their difficulties they face with the explicit solutions and strategies.

Magno (2015) conducted a study that aimed to test the model of Zimmerman \& Kitsantas (1999), which shows the transformation of processes to outputs at the writing process in English. The researcher used two tools: Academic Self-Regulated (A-SRL-S) and the revised questionnaire learning processes (R-LPQ) Questionnaire. The tools have been applied (294) university students majoring in English, communication, literature, and media in the Metropolitan District in Manila, Philippines. The results showed a statistically significant correlation between learning and self-regulation among all the factors studied, except the environmental infrastructure.

\section{Commentary on the previous studies and research:}

Throughout reviewing previous studies and research that dealt with the subject of self-organized learning, we can note the following: The common denominator among these research studies and the current study is to emphasize the significance of the use of a self-organized learning in the teaching process and that it acts more effectively than ordinary methods. It is through the presentation of this research, we find that some of it pointed to the effectiveness of self-organized learning through educational modules, reflection maps, educational program and problemsolving strategies. Self-organized learning studies were conducted at different stages of learning. Most previous studies have focused on the study of aspects of self-organized learning mainly.

\section{Method}


The researchers selected a descriptive approach, where the study is based on a descriptive scientific approach along with its major steps; for its consistency and proportionality with the nature of this research and its relevance to the objectives; as it is the appropriate method to the nature of this study.

\subsection{Population and Sample}

The study population consisted of all first secondary students in the public schools of the Directorate of Education of Amman for the second academic year 2015/2016, with a number of (925) student. Due to the limited population of the study, the sample consisted of the entire study population. The questionnaire prepared for this purpose was distributed where the researcher distributed (921) questionnaires. The following Table shows the distribution of members of the study according to the study variables.

Table (1). The distribution of the study sample according to the study variables is below

\begin{tabular}{llll}
\hline Grade & Male & Female & Total \\
\hline Academic Track & 269 & 288 & 557 \\
Career & 189 & 179 & 368 \\
Total & 458 & 467 & 925 \\
\hline
\end{tabular}

\subsection{Research Instrument}

The study tool and the stages of its design:

Questionnaire:

The researcher used a questionnaire that is appropriate for the nature of the study and its objectives in terms of effort and the potential and size of the study population.

Steps for designing and constructing the questionnaire of study:

To build a questionnaire study researcher follows these steps:

- Identifying the recourses of the construction of the tool of the study (The questionnaire) where the researcher adopted on the following:

- Access theoretical and educational literature on the topic and previous studies, periodicals and magazines, educational and research.

- Interview a group of specialists in this field to take advantage of their expertise.

- Researchers' experience through their work on the educational field.

Based on the study problem, objectives, questions, and in the light of the theoretical framework and previous studies, the former steps mentioned, the researcher formulated the initial questionnaire with its image consisting of (59) items. At the end of the paragraphs of each axis, the researchers put an open question to provide an opportunity for respondents to add the appropriate paragraphs that correspond to each axis of the questionnaire axes.

\subsubsection{Validity}

The researchers presented the tool on a group of arbitrators whose number was (11) of specialists and experts on the level of Jordanian universities where they were communicated with a speech stating the problem of the study and its objectives and questions and were asked to express their views and comments on the study, utility and clarity of each phrase and safety of linguistic formulation and suitability for achieving the goals which they put for. Through the views of the arbitrators about the tool, formulation, size and extent of agreement regarding the study questions, opinions, the following results appeared,

- A big volume of the tool of the study was noticed thus leading to boredom for some the respondents, accordingly some paragraphs and phrases were reconsidered.

- The researchers made some corrections on the directions of arbitrators and their comments.

- A set of paragraphs and phrases were modified in terms of additions and deletions.

- The amendment process was repeated several times until the resolution is finalized.

\subsubsection{Reliability}


In order to extract the reliability coefficients values in the current study it has been applied on a prospective sample of high school students (30), through the test and re-test method at intervals of a time frame of two weeks between the first two applications and the second, and the value of repetition Stability through the Pearson correlation coefficient (0.88).

\subsection{Application Procedures}

Procedures for the Application of the study passed and in the following process steps:

- Access to the literature on this subject and specialized learning self-regulator in order to benefit from the theoretical framework for these studies, while the researcher focused on the readings of the following studies: (Omari 0.2013; Banna 0.2013; Caliph al., 2007) along with other studies. The questionnaire was built and determined by depending on the researchers observations about the theoretical literature.

- The veracity of the study tool was confirmed by offering arbitration, and presented to a group of specialists.

- Subsequently, the sample was selected.

\subsection{Statistical Methods Used}

To answer questions about the study, the researcher conducted statistical analyzes as follows: To answer the first question: averages and standard deviations were calculated on the paragraph level and field. While answering the second question concerning the disclosure of the differences between the study sample responses with the degree possession of first secondary grade students of the components of self-organized learning variable depending on the study, a (t-test) was used.

\section{Results and Discussions}

\subsection{Results Related to Answer the First Question}

What degree possession of first grade secondary students of the components of self-organized learning in mathematics curriculum?

It has the answer to this question by calculating the averages and standard deviations for the variables studied are as follows:

- Environment and behavior management hub

Averages and standard deviations of the paragraphs of the environment and behavior management axis were calculated as it is appeared in (Table 2).

Table 2. Note: Averages and standard deviations of the paragraphs of the environment and behavior management axis in descending order according to averages.

\begin{tabular}{|c|c|c|c|c|c|}
\hline Rank & No. & Paragraph & Average & SD & PD \\
\hline 1 & 14 & I motivate myself to detect errors and edit & 2.86 & 1.14 & High \\
\hline 2 & 1 & I think about the proper way to study before I start & 3.84 & 1.19 & high \\
\hline 3 & 12 & $\begin{array}{l}\text { Refine your mistake when they do not succeed in mastering } \\
\text { learning course material }\end{array}$ & 3.83 & 1.14 & high \\
\hline 4 & 13 & Do enough to acquire new study skills & 3.79 & 1.12 & high \\
\hline 5 & 5 & I care my items organized school & 3.77 & 1.20 & high \\
\hline 6 & 11 & $\begin{array}{l}\text { I keep my papers are not able to control and monitor the } \\
\text { progress made during two attempts to achieve my goals }\end{array}$ & 3.70 & 1.19 & high \\
\hline 7 & 8 & $\begin{array}{l}\text { I encourage myself to continue to study when I cannot know } \\
\text { what the idea in mathematics }\end{array}$ & 3.69 & 1.19 & high \\
\hline 8 & 3 & I plan optimally to accomplish work tasks in a timely manner & 3.64 & 1.16 & medium \\
\hline 9 & 10 & I give myself enough time to achieve the goals set by & 3.63 & 1.19 & medium \\
\hline 10 & 2 & I Study mathematics in a quiet place & 3.61 & 1.20 & medium \\
\hline 11 & 15 & Follow the steps to help me continue studying mathematics & 3.61 & 1.19 & medium \\
\hline 12 & 7 & We set goals to be achieved through mathematics & 3.59 & 1.19 & medium \\
\hline 13 & 6 & $\begin{array}{l}\text { We employ the available resources of the files and folders to } \\
\text { organize learning mathematics }\end{array}$ & 3.53 & 1.20 & medium \\
\hline 14 & 4 & $\begin{array}{l}\text { I held myself to know the level of learning through the } \\
\text { curriculum for mathematics }\end{array}$ & 3.45 & 1.23 & medium \\
\hline 15 & 9 & I make sure to study mathematics before playing with my peers & 2.41 & 1.22 & Medium \\
\hline
\end{tabular}


Table (2) shows the arithmetic mean of the paragraphs, a first secondary students grades of self-organized learning mathematics curriculum, which ranged from (3.41-3.86) and reached a total score of their estimates (3.66) and the degree possession of a medium according to the approved in this study the standard, and can be seen from the Table former get (7) paragraphs of the high estimates in terms of possession, while I got (8) over medium paragraphs estimates. Paragraph scored (14), which reads "motivate myself to discover my mistakes and modified" in the first place and an arithmetic mean was (3.86), followed by paragraph (1), which reads, "I think of the way appropriate to study before I start" and an arithmetic mean was (3.84). And then paragraph (12), which reads, "I identify the mistake when they do not succeed in mastering learning course material." And arithmetic means (3.83). Paragraph (9), which reads, "I make sure to study mathematics before playing with my peers," was the last rank with a mean of (3.41) showing possession of a medium.

The researchers attributed the medium results to lack of awareness or knowledge of most of the sample selforganized learning strategies because these strategies are more closely related to the actual performance of the students. The different results of this study with the results of Wesal Omari study (2013), showed that the degree of owning a student of the components of a self-organized learning was high in the field of learning and behavior management environment.

Averages and standard deviations of the paragraphs of the research and learning information axis were calculated as it is appeared in (Table 3).

Table 3. Note: averages and standard deviations of the paragraphs of the focus of research and learning information in descending order according to averages.

\begin{tabular}{|c|c|c|c|c|c|}
\hline Rank & No. & Paragraph & Average & SD & PD \\
\hline 1 & 22 & I quit hard questions & 4,00 & 1.80 & High \\
\hline 2 & 21 & I identify expected questions & 3.88 & 1.16 & high \\
\hline 3 & 16 & Pose questions on maths teacher when I don't understand & 3.83 & 1.22 & high \\
\hline 4 & 24 & Get well-prepared for exams & 3.73 & 1.22 & high \\
\hline 5 & 17 & Revise material and previous assignments when I face problems & 3.65 & 1.20 & medium \\
\hline 6 & 28 & Have curiosity to know how to use devices in classroom. & 3.63 & 1.25 & medium \\
\hline 7 & 23 & $\begin{array}{l}\text { Look for other sources of internet that provide me with } \\
\text { information }\end{array}$ & 3.53 & 1.27 & medium \\
\hline 8 & 26 & $\begin{array}{l}\text { I ask my self a sum of questions during the lesson and try to } \\
\text { answer them }\end{array}$ & 3.53 & 1.30 & medium \\
\hline 9 & 20 & I depend on my notes that I write down & 3.52 & 1.27 & medium \\
\hline 10 & 30 & I do questions for previous years & 3.52 & 1.31 & medium \\
\hline 11 & 31 & I do the questions at the end of each chapter & 3.52 & 1.26 & medium \\
\hline 12 & 18 & I use images & 3.49 & 1.23 & medium \\
\hline 13 & 19 & $\begin{array}{l}\text { We employ the available resources of the files and folders to } \\
\text { organize learning mathematics }\end{array}$ & 3.53 & 1.20 & medium \\
\hline 14 & 25 & $\begin{array}{l}\text { I held myself to know the level of learning through the } \\
\text { curriculum for mathematics }\end{array}$ & 3.39 & 1.37 & medium \\
\hline & 29 & I make sure to study mathematics before playing with my peers & 3.38 & 1.38 & Medium \\
\hline Medium & 1.09 & 2.66 & \multicolumn{3}{|c|}{ Total Degree } \\
\hline
\end{tabular}

Table (3) shows the arithmetic mean of the paragraphs of the degree of first-grade secondary students possession of the components of self-organized learning of mathematics curriculum for the center of research and information learning have ranged from (3.21- 4.00), while the total score of their estimates reached (3.57). It can be noted from the previous Table for paragraph 4 on the high estimates in terms of possession, while I got (13) items on medium estimates. Paragraph (22) Came next which reads, "I leave difficult questions to the end of the exam and then come back to it" in the first place and an arithmetic mean was (4.00), followed by paragraph (21), which reads, "I set the expected questions in the math test substance" and an arithmetic mean was (3.88). And then paragraph (16), which reads "I ask questions on mathematics teacher when I feel Bam understand some things" with a mean (3.83). Then paragraph (24) which reads "I prepare well for tests and lessons by reading the lessons and records" followed by, with a mean (3.73). While paragraph No. 32 came, which reads "devote a certain time I go to the library in order 
to develop the scientific abilities," the last rank and a mean (3.21) degree possession of a medium.

The reason why the arithmetic mean of the paragraphs of the degree of first-grade secondary students' possession of the components of self-organized learning of mathematics curriculum was very little can be attributed to the weakness of the students' understanding of the importance of the information they get from others, such as teachers, parents and other sources. The reason may be due to get some paragraphs on the degree of owning high to be selforganized learning components represent the necessities needed for learners from their perspective, including what must be acquired in the early stages of the study, and these skills should teachers and the family of the development of learners and us is acquired by a self-student. The current results of this study are different from the results of Wesal Omari's study (2013), which showed the arithmetic mean of the paragraphs of the degree of first-grade secondary students possession of the components of self-organized learning of mathematics curriculum were high.

Averages and standard deviations of the paragraphs of the organizational behavior is adaptive axis were calculated as it is appeared in (Table 4).

Table 4. Note: Averages and standard deviations of the paragraphs of the axis of organizational behavior are adaptive in descending order according to averages

\begin{tabular}{|c|c|c|c|c|c|}
\hline Rank & No. & Paragraph & Average & SD & PD \\
\hline 1 & 39 & $\begin{array}{l}\text { I quit hard studying when I don't } \\
\text { understand }\end{array}$ & 3,48 & 1.28 & medium \\
\hline 2 & 41 & I hate difficult words to memories & 3.46 & 1.30 & medium \\
\hline 3 & 35 & $\begin{array}{l}\text { Respond when my friends interrupt me } \\
\text { while studying }\end{array}$ & 3.45 & 1.30 & medium \\
\hline 4 & 45 & I lose significant points during the period & 3.42 & 1.31 & medium \\
\hline 5 & 33 & $\begin{array}{l}\text { I delay studying math till the last } \\
\text { moments. }\end{array}$ & 3.41 & 1.42 & medium \\
\hline 6 & 40 & $\begin{array}{l}\text { Forget to take notes on the discussion } \\
\text { when I face difficulty in understanding. }\end{array}$ & 3.39 & 1.30 & medium \\
\hline 7 & 36 & $\begin{array}{l}\text { I ignore scientific subjects when I don't } \\
\text { understand }\end{array}$ & 3.37 & 1.32 & medium \\
\hline 8 & 38 & $\begin{array}{l}\text { I ignore posing questions during math } \\
\text { class about difficult things. }\end{array}$ & 3.37 & 1.30 & medium \\
\hline 9 & 34 & I miss equipments of maths & 3.33 & 1.30 & medium \\
\hline 10 & 37 & I avoid taking classes privately. & 3.33 & 1.34 & medium \\
\hline 11 & 43 & $\begin{array}{l}\text { I depend on my colleagues in solving } \\
\text { assignments }\end{array}$ & 3.52 & 1.45 & medium \\
\hline 12 & 44 & I discard any math related matter. & 3.30 & 1.45 & medium \\
\hline 13 & 46 & $\begin{array}{l}\text { I feel bored when I revise the math } \\
\text { material }\end{array}$ & 3.27 & 1.36 & medium \\
\hline 14 & 47 & I always go late to maths class & 3.25 & 1.38 & \\
\hline 15 & 42 & $\begin{array}{l}\text { Ask for lots of exist permission and } \\
\text { recesses }\end{array}$ & 3.12 & 1.51 & $\begin{array}{l}\text { medium } \\
\text { Medium }\end{array}$ \\
\hline Medium & 1.09 & 2.66 & Total Degree & & \\
\hline
\end{tabular}

Table (4) shows that the arithmetic mean has ranged from (3.12-3.48), and reached the total score of their estimates (3.33) and the degree possession was medium. Paragraph (39) which reads, "I leave the study of mathematics when I feel not to be understood" came in the first place with an arithmetic mean (3.48), followed by paragraph (41), which reads "complain of repeating difficult words so many times I have saved it," and an arithmetic mean was (3.46). And then paragraph (35), which reads, "will answer when the intersection of my friends during the study of mathematics," a mean (3.45). Paragraph (45), which reads "during class time is lost to me important points because I was thinking about other things," came next with a mean of (3.42). While paragraph (48), which reads, "more than one authorization and out of its quota during the studied mathematics" came the last rank and a mean (3.12) and the degree possession of a medium. The researcher attributed the reason to the fact that the study sample requires infrastructure and the provision of technical capabilities. The results of this study are consistent with the results of Wesal Omari's study (2013), which showed that the possession degree first secondary students of were 
intermediate in the field of organizational behavior. The results differ from Baratontib and Thenwno (Pratontep \& Chinwonno, 2014 Study) which showed that the possession of students learning strategies organized self was high.

\subsection{Results Related to Answer the Second Question}

Are the study samples responses in the possession degree of first grade secondary students of the components of self-organized learning in mathematics curriculum vary depending on the variables of gender and the type of track?

3.2.1 A Variable Gender To answer the study question on gender variable the arithmetic means and standard deviations for the areas were calculated; Table (5) shows that.

Table 5. Note: Averages, standard deviations, and the results of the test (T) of the responses of the study sample in the degree possession of first grade secondary students of the components of self-organized learning in mathematics curriculum depending on variable gender

\begin{tabular}{lllllll}
\hline FIELD & GENDER & NO. & AVERAGE & SD & T & Sig. \\
\hline $\begin{array}{l}\text { Environment } \\
\text { and behavior }\end{array}$ & $\mathrm{M}$ & 369 & 2.20 & .438 & .256 & .683 \\
$\begin{array}{l}\text { management } \\
\text { Research and }\end{array}$ & $\mathrm{M}$ & 288 & 2.19 & .452 & & \\
$\begin{array}{l}\text { learning data } \\
\text { F }\end{array}$ & 269 & 2.73 & .260 & -.593 & .282 \\
$\begin{array}{l}\text { Non-adaptive } \\
\text { organizing }\end{array}$ & $\mathrm{M}$ & 288 & 2.75 & .243 & & .937 \\
behavior & $\mathrm{F}$ & 269 & 2.53 & .324 & .044 & \\
\hline
\end{tabular}

Results in the Table (5) indicated that there is no statistically significant differences at the significance level $(0.05$ $=\alpha$ ) in the study sample responses to the point of possessing a first-grade secondary students of the components of self-organized learning in mathematics curriculum depending on the variable of gender. The reason is attributed for the progress in the academic level of the student; therefore the student should be more aware and mature. We realize that the scientific knowledge are cumulative, which requires them to pursue mathematics accurately. Thus, the gender variable will have no effects at this age.

The researchers attribute the lack of statistically significant differences to the nature of academic preparation in the first secondary grade as well as requirements needed. The different results of this study with the results of Wesal Omari study (2013), which showed no statistically significant differences in the degree of students' possession of the components of a self-organized learning attributed to the classroom.

3.2.2 Variable Track Type To answer the study question on variable track type the arithmetic means and standard deviations for the areas were calculated as shown in Table (6)

Table 6. Note: Averages, Standard Deviations, and the results of the test (T) of the responses of the study sample in the possession degree of first grade secondary students of the components of self-organized learning in mathematics curriculum depending on the type of a variable track

\begin{tabular}{lllllll}
\hline Fields & Pattern & No. & Average & SD & T & SIG \\
\hline Environment Management & Academic & 189 & 2.21 & .452 & & .728 \\
& & & & .538 & \\
Research and Data System & Professional & 179 & 2.18 & .433 & & \\
& Academic & 189 & 2.73 & .254 & & \\
& Professional & 179 & 2.75 & .251 & -.698 & .626 \\
Non-Adoptive organizational behavior & & 189 & & .322 & & .838 \\
& Professional & & 2.53 & & -.114 & \\
& Academic & 179 & 2.53 & .325 & & \\
\hline
\end{tabular}


Results contained in the Table (6) indicated that there is no statistically significant differences at the significance level $(0.05=\alpha)$ in the study sample responses in the possession degree of first secondary grade students of the components of self-organized learning in mathematics curriculum depending on the type of a variable domain. The researcher believes that the reason for this may be due to the awareness of the first secondary grade academic and vocational students of the importance of self-organized learning, understanding of the plan. This can be interpreted that self-organized learning consists of components and includes a subset key strategies which look particularly for achievement and self-organized learning that includes necessary and important cognitive strategies, which, in turn, could be great achievement for learners, a thing which will increase the academic progress and age.

The different results of this study don't match with the results of Wesal Omari study (2013), which showed no statistically significant differences in the degree of students' possession of the components of a self-organized learning attributed to the classroom.

\section{Recommendations}

In light of the findings of the study results, we recommend the following

- Including high school mathematics curriculum in particular and other study curricula in general in the stages of scientific education activities and training in order to enhance the potential of students to practice self-organized learning strategies.

- Directing educational efforts of the Ministry of Education about the level of schools to activate and follow the development of self-regulation among students.

- Directing research efforts in Jordanian universities for further studies in collaboration with schools around the study of self-organized learning have different descriptive levels, and follow changes in students.

- The need for the high school math teachers

- educating students about the importance of self-organized learning components, and its impacts on academic achievement.

\section{References}

Al-Farhan, E. (2014). Effectiveness of the proposed strategy based on self-organized learning in science to develop habits of mind and self-regulation skills for students of average third grade with different learning styles. Otrojh graduate unpublished, Umm Al Qura University, Makkah, Saudi Arabia.

Bandura, A. (1986). Social foundation of thoughtand action: A social cognitive theory. Upper Saddle River, NJ: Prentice Hall.

Banna, M. (2013). A proposed strategy in a self-organized learning for the development of self-regulation skills and achievement in math at the third grade preparatory students. Journal of Mathematics Educations light, XVI folder.

Castello, M. (2014). Toward Self-Regulated Academic Writing: An Exploratory Study with graduate Students in a Sustained Learning Environment. Electronic Journal of Research in Educational psychology, 7(3), 1107-1130.

Ghadhban, P. (1996). The impact of live models and televised and written on the moral judgments to the basic sixth grade students. Unpublished MA Thesis, University of Jordan: Amman, Jordan.

Ghanem, n. (2007). The impact of a training program in self-organized learning based social cognitive learning in the internal motivation and self-efficacy among seventh grade students theory. PhD Thesis: University of Jordan, Amman.

Hashim, T. (2014). Model teaching proposal is based on the strategic learning and its effectiveness in the development of achievement and skills of self-regulation among the first athlete secondary grade students. Journal of Mathematics Educations, 17(1), 6-91.

Kazim, M., \& Suhail, A. (2008). Self-efficacy and its relationship with the chaotic behavior among middle school students. Magazine, (72), S41-48.

Khalifa, W. (2007). The impact of an educational program in the light of some self-organized learning strategies to solve math problems and defended academic achievement among students talented low achievement in mathematics. Journal of the College of Education, 2, p. 37, (2007), 246-292.

Kitami, J. (2004). Social cognitive theory and its applications. Amman: Dar thought for publication and distribution.

Kitami, J., \& Yousuf, T. (2010). Social intelligence in children. Amman: Dar soft for publication. 
Lepper, M. (2005). Intrinsic and Extrinsic Motivational Orientations between Self-rated Motivation and Memory Performance. Scandinavian Journal of Psychology, 46(4), 323-330.

Magno, C. (2015). Self-Regulation and Approaches to Learning in English Composition Writing. TESOL Journal, $1,1-16$.

Ngor, M. (2013). The impact of interactive software based on computer simulations of three-dimensional geometric shapes in the development of visual thinking and learning skills of self-organized second grade students of middle-Baha. Journal of Mathematics Educations, 16, Part 1(2013), 30-104.

Nofal, O. (2011). After a strategy based on self-regulation directed at the development of self-organized learning skills in the chemistry of the first year of secondary students, a message posted Ph.D., Journal of Research in Education, Year 2011, GS 12, pp: 999-1029.

Omari, T. (2013). Degree possession of graduate students the basic phase of Irbid area of the components of a selforganized learning in the science curriculum in light of some variables. Journal of the Islamic University of Educational and Psychological Studies, atheist Twenty-Volume, IV, 127-S95.

Paris, S. G., \& Paris, A. H. (2001). Classroom Applications of Research on Self-Regulated. Educational Psychologist, 36(2), 89-103.

Pintrich, P. R. (1999). The role of motivation in promoting and sustaining self-regulatedlearning. International Journal of Educational Research, 31, 459-470.

Pintrich, P. R. (2005). The Role of Goal Orientation is Self-Regulated Learning. In Boekaerts, M., Pintrich, P. R. \& Zeidner, M. (Eds.), Handbook of Self-Regulation (pp. 31-86). San Diego: Elsevier Academic Press.

Pratontep, C., \& Chinwonno, A. (2014). Self-Regulated Learning by Thai University Students in AN EFL Extensive Reading Program. Journal of Humanities, 11(2), 104-124.

Schunk, D. (2005). Learning Theories: An Educational Perspective. $4^{\text {th }}$ Edition. Upper Saddle River, NJ: Merrill / Prentice Hall.

Schunk, D. H. (2000). Enhancing strategy use: Influences of strategy value and goalorientation. Paper presented at the American Educational Research Association, Atlanta. GA.

Zimmerman, B. J. (1990). Self-regulated Learning and Academic Achievment: An Overview. Educational Psychologist, 25, 3-17.-

Zimmerman, B. J. (2006). Attaining Self-regulation: A Social Cognitive Perspective. In Boekaerts, M., Pintrich, P., \& Zeidner, M. (Eds.), handbook of Self-regulation (pp. 13-39). San Diego: Elsevier Academic Press.

\section{Copyrights}

Copyright for this article is retained by the author(s), with first publication rights granted to the journal.

This is an open-access article distributed under the terms and conditions of the Creative Commons Attribution license (http://creativecommons.org/licenses/by/4.0/). 